\title{
Article
}

\section{Effect of the Connecting People Intervention on Social Capital: A Pilot Study}

Webber, Martin, Morris, David, Howarth, Sharon, Fendt-Newlin, Meredith, Treacy, Samantha and McCrone, Paul

Available at http://clok.uclan.ac.uk/21520/

Webber, Martin, Morris, David ORCID: 0000-0001-7372-8084, Howarth, Sharon, Fendt-Newlin, Meredith, Treacy, Samantha and McCrone, Paul (2019) Effect of the Connecting People Intervention on Social Capital: A Pilot Study. Research on Social Work Practice, 29 (5). pp. 483-494. ISSN 1049-7315

It is advisable to refer to the publisher's version if you intend to cite from the work. http://dx.doi.org/10.1177/1049731517753685

For more information about UCLan's research in this area go to http://www.uclan.ac.uk/researchgroups/ and search for <name of research Group>.

For information about Research generally at UCLan please go to http://www.uclan.ac.uk/research/

All outputs in CLoK are protected by Intellectual Property Rights law, including Copyright law. Copyright, IPR and Moral Rights for the works on this site are retained by the individual authors and/or other copyright owners. Terms and conditions for use of this material are defined in the policies page.

\section{CLoK}

Central Lancashire online Knowledge www.clok.uclan.ac.uk

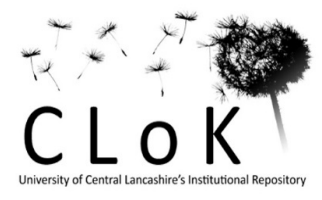




\title{
Effect of the Connecting People Intervention on social capital: a pilot study
}

\author{
Martin Webber \\ Professor of Social Work, Department of Social Policy and Social Work, University of York, \\ Heslington, York, YO10 5DD, United Kingdom, martin.webber@york.ac.uk, tel. +44(0)1904 \\ 321203 \\ David Morris \\ School of Social Work, University of Central Lancashire \\ Sharon Howarth \\ School of Health, University of Central Lancashire \\ Meredith Fendt-Newlin and Samantha Treacy \\ Department of Social Policy and Social Work, University of York \\ Paul McCrone \\ Institute of Psychiatry, Psychology and Neuroscience, King's College London
}

\section{Author Note}

This paper presents independent research funded by the NIHR School for Social Care Research (T976/T11-017/KCLMW). The views expressed in this paper are those of the authors and not necessarily those of the NIHR School for Social Care Research or the Department of Health, NIHR or NHS. The authors would like to gratefully acknowledge the time given by the participants in this study and would like to thank their agencies for providing us with access to their expertise.

Correspondence concerning this article should be addressed to Martin Webber, Department of Social Policy and Social Work, University of York, Heslington, York, YO10 5DD, United Kingdom, martin.webber@york.ac.uk,tel. +44(0)1904 321203

Keywords: social capital; social networks; mental well-being; pre-experimental design, complex intervention; mental health 


\title{
Effect of the Connecting People Intervention on social capital: a pilot study
}

\begin{abstract}
Objective: This pilot study evaluated the effect of the Connecting People Intervention (CPI) on access to social capital, social inclusion and mental well-being.

Method: A prospective one group pretest-posttest pre-experimental study of 155 people with a mental health problem or a learning disability receiving care and support from health and social care practitioners trained in the CPI was used.

Results: Participants exposed to practice with high fidelity to the CPI model had significantly higher access to social capital $\left(p=.03\right.$, partial $\left.\eta^{2}=.05\right)$ and perceived social inclusion $(p=.01$, partial $\left.\eta^{2}=.07\right)$, and lower service costs $(-£ 1,331(95 \% \mathrm{CI}=-£ 69$ to $-£ 2593)$, posttest than those exposed to low fidelity to the model. All participants had significantly higher mental wellbeing posttest $(\mathrm{p}<.001)$.
\end{abstract}

Conclusions: These preliminary results suggest that when fully implemented the CPI can improve social outcomes for people with a mental health problem or learning disability. 
Social capital is recognised as important for health and mental well-being (Kawachi, Subramanian, \& Kim, 2007). Defined by Nan Lin and others as the resources that are embedded within social networks (Lin, 2001; Lin \& Erickson, 2008), social capital can lead to greater occupational prestige, income and political influence when mobilized (Lin, 2001). This conception is an extension of social network theory and emphasizes the importance of network members' resources, such as wealth, power and status, to an individual. It differs from communitarian notions of social capital (e.g. Putnam, 1993) as its predominant focus is on the benefits which accrue to individuals rather than to groups.

Lin (2001) suggested that individuals can anticipate returns from their investment in social relationships through four mechanisms, which may improve their mental health. Firstly, the provision of expert information from network members about the most effective interventions or health behaviours (Song \& Chang, 2012; Zambon et al., 2010) or employment opportunities (Flap, 1999), for example, can promote recovery. Secondly, the power and authority of network members may exert an influence on exposure and vulnerability to health risks which is similar to individually possessed power and social ordering (Song, 2015). Thirdly, network members' resources may act as social credentials and could contribute to health and social care (Song, 2011), or could help to alleviate deprivation or provide new opportunities (Lin, 2001). Fourthly, network members' resources can reinforce an individual's identification with a group and help to maintain subjective social status (Song, 2015), which can help to promote mental health (Leu et al., 2008). Individuals are motivated to protect themselves against possible losses of personal resources and they are likely to access network members' resources in order to help them do so (Lin, 2001). However, people experiencing long term mental health problems or short term psychological distress have access to less social capital, measured using either the Resource 
Generator (Webber \& Huxley, 2007) or Position Generator (Lin \& Dumin, 1986) than the general population (Dutt \& Webber, 2010; Henderson et al., 2014; Song, 2011; Webber \& Huxley, 2007; Webber, Huxley, \& Harris, 2011). This inequality in access to social resources from families, networks and communities for people with mental health problems has been observed across the life course from childhood and adolescence (McPherson et al., 2014), though adulthood (Almedom \& Glandon, 2007) into older age (Sun, Liu, Webber, \& Shi, 2017). Hobfoll's (1998) conservation of resources theory, which connects the loss of resources with increasing levels of stress, provides a plausible mechanism for the correlation of low levels of social resources with high prevalence of mental health problems.

Many people with severe and enduring mental health problems, such as severe depression, schizophrenia or bi-polar disorder, who are excluded from opportunities to live, work, engage with others and enjoy recreational activities which others take for granted (Boardman, 2011; Sayce, 2000), face difficulties in establishing social relationships. People with a learning disability experience similar problems (Bates \& Davis, 2004; Bigby \& Wiesel, 2011). This is partly due to impaired social functioning (Stain et al., 2012), but is also a result of discrimination often caused by stigma (Evans-Lacko, Henderson, \& Thornicroft, 2013; Schomerus et al., 2012). Stigma works to sustain exclusion through the conception of others and through internalised self-stigma of the 'uselessness' of people with mental health problems (Thornicroft, 2006). Experiences of discrimination are associated with reduced access to social capital for people with severe and enduring mental health problems (Webber et al., 2014) and reduced levels of trust and social support among people with severe depression (Zoppei et al., 2014). However, there is also evidence of social networks shrinking prior to the onset of psychosis (Gayer-Anderson \& Morgan, 2013).

Loneliness and social isolation increase the likelihood of mortality (Holt-Lunstad, Smith, Baker, Harris, \& Stephenson, 2015), but supporting people to strengthen their 
networks and connections with their local community is often afforded a low priority by many practitioners (McConkey \& Collins, 2010). A key role of mental health social workers in the United Kingdom is to work co-productively and innovatively with local communities to support active citizenship and social inclusion of people with mental health problems (Allen, 2014). Additionally, developing social networks that promote health and well-being has been endorsed as a key priority for mental health social workers in England (Department of Health, 2016), as in many other countries which have enacted legislation promoting more socially inclusive policy and practice (e.g. Carter, Satcher, \& Coelho, 2013; Coombs, Nicholas, \& Pirkis, 2013; Fiorillo et al., 2013). However, in spite of the importance of social interventions, they are often neglected in social work research (Jenson, 2014).

There is some evidence that community engagement interventions produce subjective gains in physical and psychological health, self-confidence and social relationships, but can cause stress and drain an individual's energy levels (Attree et al., 2011). Initiatives such as voluntary work (Murray, Easter, \& Bellringer, 2007) and time banks (Collom, 2008), where a person undertakes tasks for another in exchange for someone else's time, promote social interaction in non-stigmatised locations and help marginalised people to enhance their access to social capital. Additionally, participation in community leisure activities helps people to improve their social connections, health and positive emotions (Iwasaki, Coyle, \& Shank, 2010); develop social skills and accomplish their goals (Lloyd, King, \& McCarthy, 2007) and may facilitate the development of planning and coping skills (Snethen, McCormick, \& Van Puymbroeck, 2012). However, the evidence base for community engagement interventions that promote well-being is slim (Anderson, Laxhman, \& Priebe, 2015; Webber \& FendtNewlin, 2017). For example, the authors' reviews of interventions to enhance the social networks and social participation of adults with mental health problems (Newlin, Morris, Howarth, \& Webber, 2015) and learning disabilities (Howarth, Morris, Newlin, \& Webber, 
2016) included 25 interventions overall. The overall quality of the evidence was poor and findings were equivocal.

The lack of evidence, practice models or frameworks to assist practitioners to support people to develop their networks, and hence their access to social capital, led the authors to develop an intervention informed by Medical Research Council guidelines (Medical Research Council, 2008). They used ethnographic methods to capture existing good practice and the full complexity of the processes involved in supporting people to enhance their social networks in order to develop an intervention model amenable to future experimental evaluation (Webber, 2014). They found that a person-centred approach building upon the person's strengths and supporting them to engage in new activities within their communities appeared feasible and effective (Webber, Reidy, Ansari, Stevens, \& Morris, 2015). The subsequent intervention model, named the Connecting People Intervention (CPI), was developed through focus groups and a Delphi consultation with an expert panel (Webber, Reidy, Ansari, Stevens, \& Morris, 2016). It represented a complex co-productive process involving the practitioner and service user setting goals, discovering new opportunities for social engagement and support to develop new social relationships.

This study aimed to pilot the CPI in a diverse range of health and social care settings to evaluate outcomes for service users. Additionally, it aimed to pilot the CPI in different client groups (adults with mental health problems and adults with a learning disability) to evaluate its transferability across social care client groups. This study explored the following hypotheses:

1) (a) There will be a statistically significant pretest to posttest mean change of the three main outcomes (access to social capital, social inclusion and mental well-being) for participants experiencing high fidelity CPI. 
(b) The change in pretest to posttest scores on the three main outcomes for participants experiencing high fidelity CPI will be significantly higher than those who experience low or moderate fidelity CPI.

(c) The change in pretest to posttest scores on the three main outcomes will remain statistically significant after controlling for pretest scores and sample characteristics.

2) The overall service cost of high fidelity CPI will be significantly lower than low or moderate fidelity CPI.

3) The quality-adjusted life years of people experiencing high fidelity CPI will be significantly higher than those experiencing low fidelity CPI.

\section{Methods}

\section{Study design}

This study used a prospective one group pretest-posttest pre-experimental design to pilot the CPI. Randomisation to an intervention or control group was not justified as there was no critical equipoise due to a lack of data on the efficacy of the CPI. A control group was considered but not used because it was possible that some aspects of the practice articulated in the CPI may be present in the control group without the intervention training being provided. For example, some practitioners may already work alongside people to help them establish new social relationships. Instead, it was decided that the intervention training would be provided to all participating teams and outcomes would be evaluated according to fidelity to the CPI model.

\section{The Connecting People Intervention}

The CPI (Webber et al., 2016) is an enhancement to usual care as it provides guidance to health and social care practitioners on how to more effectively help service users to 
develop their social networks. At its heart is a co-productive process of the practitioner and service user setting goals together and identifying opportunities for new social engagement. The focus of the work is on identifying potential new networks to engage the person with and supporting them to make new connections. The CPI requires an organisational commitment from teams to become more fully embedded within their local communities, and for team leaders to foreground the CPI model in team meetings and individual supervision. Practitioners are expected to use the model to inform their daily practice with all service users. The CPI model is not prescriptive about the steps the practitioner needs to take, but the practice guidance provides examples and advice to inform the process of engaging service users with their community (geographical, interest or personal).

As the CPI was initially developed out of practice with working-age adults with mental health problems (Webber et al., 2015), we held focus groups with adults with a learning disability and older adults with a mental health problem, and practitioners who worked with them, to explore the applicability of the CPI to them. These groups made no recommendations for changing the model as they found it equally applicable to them. However, they helped the research team to design information leaflets to explain to service users what the CPI model was.

Training. Two-day training was provided to participating teams in the CPI in sessions led by a team of five trainers (two to three per session). Whole-team training was provided to 108 workers across all agencies which included social care workers, social workers, nurses, psychologists, occupational therapists, psychiatrists and team managers, according to the composition of participating teams. The training included an introduction to the model and an exercise in mapping their existing practice onto it. Gaps in knowledge and skills were identified and bespoke training was provided to teams according to their needs. This included case discussions, group problem-solving and studying the CPI practice 
guidance manual, which was provided to practitioners in hardcopy to support their practice. Teams created action plans and personalised CPI models during the training sessions to discuss at future team meetings and to be used in subsequent staff inductions. The trainers provided on-going support and a follow-up training session to teams as required to support the implementation of the model in practice.

\section{Setting}

Using social media (Twitter and blog posts), and the United Kingdom Mental Health Research Network, we offered health and social care agencies working with adults with mental health problems or a learning disability in England the opportunity to participate in the study. A total of 25 agencies nominated themselves and self-completed a screening questionnaire which asked about their existing practice; their ability to readily adapt to the requirements of the intervention; their ability and readiness to support their workers in delivering it; and their ability to support the recruitment of participants to this study. From these, we recruited 16 social care agencies across England to participate and provided their teams with intervention training, of which 14 recruited participants for the study. Nine agencies were National Health Service community mental health teams, four were third sector agencies and one was a local authority day service for adults with a learning disability. Seven agencies worked only with people with mental health problems, four worked only with people with a learning disability and three worked with both service user groups. The inclusion of multiple agencies across the service user groups and diverse practice contexts aimed to make the study more naturalistic and potentially more generalizable.

\section{Participants}

Inclusion criteria. The criteria for inclusion in the study were new referrals to the agencies that met their eligibility criteria and accepted a service. The inclusion criteria were 
deliberately broad to allow us to measure the outcomes of the CPI in a heterogeneous sample. People who lacked the capacity to give informed consent to participate were excluded, though people with mild to moderate learning disabilities who were able to give informed consent to participate were included.

Recruitment and sample size. Potential participants were provided with information about the study by practitioners or Clinical Studies Officers during or soon after their initial assessments and were asked to contact a researcher if they were interested in participating. Allowing for $25 \%$ loss-to follow-up, we aimed to recruit a minimum of 40 participants in each of the three study groups (adults with mental health problems $<65$ years old; adults with mental health problems $>65$ years old; and adults with a learning disability), to provide sufficient pilot data for each user group (Lancaster, Dodd, \& Williamson, 2004).

Participant socio-demographics. 155 participants were recruited for the study, 130 (83.9\%) of whom had a mental health problem and $25(16.1 \%)$ a learning disability. We only recruited $9(5.8 \%)$ people with a mental health problem aged over 65 years old so these were grouped with the other adults with a mental health problem for analysis. 107 (69.0\%) were recruited from a statutory agency and $48(31.0 \%)$ from a third sector agency.

The socio-demographic characteristics of the sample were typical of users of specialist mental health and learning disability services in England. Most were male $(n=85$, 55.2\%) and participants ranged in age from 16 to $87(\mathrm{~m}=41.7$, s.d.=18.0). Most were of white British ethnicity $(n=125,80.6 \%)$; others were Asian $(n=15,9.7 \%)$; Black $(n=5,3.1 \%)$; or of other ethnic origin $(n=10,6.2 \%)$. Only $14(9.0 \%)$ were employed or self-employed, with most describing themselves as being unemployed or long-term sick $(n=88,56.8 \%)$. Others described themselves as retired $(n=22,14.2 \%)$, students $(n=16,10.3 \%)$, or looking after their family $(n=7,4.5 \%)$. Only $16(n=10.3 \%)$ had an annual income of more than $£ 13,500$ (half the median income in the United Kingdom) and 74 (47.7\%) had no car in their household (a key 
indicator of poverty), but only $12(7.7 \%)$ lived in the $10 \%$ of communities with the highest levels of multiple deprivation in England.

Attrition. At nine months, 117 (75.5\%) participants were followed up. Reasons for drop-out from the study were being too unwell or lacking capacity to participate $(n=8)$; choosing not to participate any longer without giving any reason $(n=7)$; moving house $(n=4)$; dying $(\mathrm{n}=1)$; and a further 18 were not contactable at follow-up.

Attrition was lower in the statutory agencies with $80.4 \%(n=86)$ followed-up in contrast to $64.6 \%(n=21)$ in the third sector agencies $\left(\chi^{2}=4.47, d f=1, p=.04\right)$, possibly because fewer remained in contact with the third sector agencies over this period. Follow-up was higher amongst women than men $\left(84.3 \%\right.$ vs $\left.68.2 \%, \chi^{2}=5.34, \mathrm{df}=1, \mathrm{p}=.02\right)$ and older participants (mean age $=43.6$ years vs 35.9 years $(t=2.38, d f=1, p=.02)$ ). There was no difference in rates of attrition according to ethnicity, service user group, employment status, multiple deprivation, car ownership or income.

\section{Measures}

The primary outcome was access to social capital which was measured using the Resource Generator-UK (RG-UK, Webber \& Huxley, 2007). In the tradition of social network measures such as the Name Generator (McCallister \& Fischer, 1978) and Position Generator (Lin \& Dumin, 1986), this instrument measures participants' access to social resources within their own social network. The RG-UK was derived from a version developed in The Netherlands (van der Gaag \& Snijders, 2005) and its items have been made culturally relevant and validated for use in the United Kingdom general population. It has good reliability and validity (Webber \& Huxley, 2007), shows responsiveness to change (Webber et al., 2011), and has been used in diverse samples of people with mental health problems in the UK (e.g. Dutt \& Webber, 2010; Webber et al., 2014) and internationally (e.g. 
Kobayashi, Kawachi, Iwase, Suzuki, \& Takao, 2013; Sun et al., 2017) producing valid results.

The secondary outcomes were social inclusion and mental well-being. Social inclusion was measured using the Social and Community Opportunities Profile (SCOPE, Huxley et al., 2012), which captures both subjective and objective dimensions of social inclusion, including items for comparison with population norms. SCOPE measures perceived opportunities available for social inclusion, satisfaction with current opportunities and perceived social inclusion. SCOPE has been validated for use with people with mental health problems or high care needs with good reliability and validity (Huxley et al., 2012). Mental well-being was measured using the Warwick-Edinburgh Mental Well-Being scale (WEMWBS, Tennant et al., 2007). WEMWBS is used as a national indicator of mental wellbeing in England (Department of Health, 2013), it produces valid and reliable results in diverse populations (Stewart-Brown et al., 2011) and is responsive to change in samples of people with mental health problems (Maheswaran, Weich, Powell, \& Stewart-Brown, 2012). Potential confounding variables were measured at posttest. Attachment style impacts on the ability of people with mental health problems to develop relationships (Webber et al., 2011). This was measured using the Relationship Questionnaire (RQ, Bartholomew \& Horowitz, 1991), a brief, valid and reliable self-report tool which has been used in diverse populations (e.g. Allen \& Baucom, 2004; Ciechanowski, Walker, Katon, \& Russo, 2002; Dieperink, Leskela, Thuras, \& Engdahl, 2001). Similarly, life events during follow-up could impact participants' ability to develop new social relationships. This was measured using the Life Events Questionnaire (LEQ, Norbeck, 1984) which collected data on both positive and negative events, and gave respondents the opportunity to provide a contextual threat rating for each. This has also been used reliably in diverse populations (e.g. Drake, Bull, \& Boon, 2008; Norbeck \& Anderson, 1989). 
Costs were calculated by collecting service use data at pretest and posttest using the Client Service Receipt Inventory (CSRI) (Beecham \& Knapp, 2001) and combining this information with appropriate unit cost information (Curtis \& Burns, 2015). Quality adjusted life years (QALYs) were estimated through use of the EQ-5D (The EuroQol Group, 1990).

Socio-demographic data were collected at pretest. Process data were collected via qualitative semi-structured interviews at posttest and will be reported elsewhere.

Data collection. Data were collected by researchers, who were independent of the clinical teams, in face to face interviews with participants. Pretest measures were taken after the participant was accepted by the team to receive a service but before they were exposed to the CPI. Posttest measures were taken nine months later using the same method after they had been exposed to practitioners trained in the CPI. Brief, valid and reliable measures were chosen to minimise respondent burden and maximise the precision of the study.

Intervention fidelity. An a priori decision was made to analyse data according to intervention fidelity. We hypothesised that outcomes would be significantly improved in teams where the intervention was implemented with high fidelity. In the absence of a control group, this was selected as the most reliable method of deducing the effect of the intervention on outcomes in this pilot study.

Fidelity to the CPI was measured through a triangulated consensus rating process by the research team which was informed by service user ratings on the CPI fidelity scale (CPIFS-SU); parallel worker ratings on the same scale (CPIFS-W); and researcher observations of the implementation of the CPI. Parallel versions of the 19-item CPIFS were administered to service users and workers at posttest; the internal consistency of both was high (Cronbach's Alpha $=0.92$ for both scales). The CPIFS asked for practice examples in five domains: community engagement; asset-based assessments; co-produced care planning; goaloriented partnership working; and relationship building. Informed by the on-going process 
evaluation, fidelity ratings were made by the research team at a consensus meeting on completion of data collection for each team participating in the study. Ratings were made on a scale of 1-9 for each of the five practice domains where 1-3=low, 4-6=medium and 79=high fidelity to the CPI model. Scores were summed to produce an overall fidelity score per team. Teams scoring 5-15 were categorised as low $(n=3) ; 16-30$ as moderate $(n=7)$; or 3145 as high $(\mathrm{n}=4)$ fidelity to the CPI model.

To create two groups for analysis we combined participants who experienced low or moderate fidelity CPI into one group $(n=87)$. These were compared with those who experienced high fidelity CPI $(\mathrm{n}=30)$.

\section{Analysis}

To compare the characteristics of the low/moderate and high fidelity groups we used chi-square statistics for the categorical variables; t-tests for normally-distributed continuous variables; and Mann-Whitney U tests for skewed variables. Paired t-tests were used to evaluate prettest to posttest changes in the primary and secondary outcomes, with alpha adjusted using the Bonferroni correction. Effect sizes were calculated using Cohen's d. Repeated measures multivariate analysis of covariance (MANCOVA) was used to control for the potential confounding effect of participant characteristics on CPI fidelity group. Effect sizes were calculated using partial $\eta^{2}$. Other methods could have been chosen to evaluate change over time, such as a linear regression of the outcome measures at two time points. However, paired t-tests were used to evaluate change in each outcome measure one at a time. Then, MANCOVA was used to adjust for multiple testing caused by using multiple outcome measures whilst controlling for potential confounding variables; and it was able to evaluate the effect of CPI fidelity group over the two time points. 
This study was reviewed and approved by the Social Care Research Ethics Committee (ref. 11/IEC08/0042).

\section{Results}

\section{High and low/moderate fidelity groups}

Participants were recruited to the study from September 2012 to May 2013 and 9month follow-up interviews were conducted from June 2013 to February 2014.

\section{Figure 1 about here}

There were no statistically significant differences between participants experiencing high fidelity CPI ( $n=30)$ and those experiencing low or moderate fidelity CPI $(n=87)$ according to service user group (mental health or learning disability), sex, ethnic group, age, employment status, multiple deprivation of local area, presence of a vehicle in the household, income levels or attachment style (table 1). $86.0 \%(n=74)$ of the low/moderate fidelity CPI group were taking psychiatric medication in contrast to $63.3 \%(n=19)$ of the high fidelity CPI

group $\left(\chi^{2}=7.22, \mathrm{df}=1, \mathrm{p}=.01\right)$, so this was controlled for in subsequent analysis. Additionally, this sub-group analysis found that those experiencing high fidelity CPI experienced a mean surfeit of 6.6 positive over negative life events during the follow-up period in comparison with 1.9 in the low fidelity group $(\mathrm{t}=2.19, \mathrm{df}=114, \mathrm{p}=.03)$. Further analysis of the role of life events on the causal pathway to improved outcomes is required.

\section{Table 1 about here}

\section{Hypothesis 1}

In testing hypothesis $1(\mathrm{a})$, paired t-tests found moderate effect sizes for pretest to postttest changes on the total RG-UK scale $(\mathrm{d}=0.51)$ and two of its sub-scales (personal skills $(\mathrm{d}=0.39)$ and problem solving skills $(\mathrm{d}=0.69)$; on SCOPE perceived social inclusion $(\mathrm{d}=0.52)$; and on WEMWBS (d=0.53) (table 2). Change in SCOPE perceived opportunities and 
satisfaction with opportunities scales were not statistically significant. Therefore, hypothesis 1(a) was largely upheld.

\section{Table 2 about here}

There was no pretest to posttest change on the RG-UK scale or its sub-scales, or SCOPE perceived social inclusion, for participants experiencing low or moderate fidelity CPI (table 2). However, there was a small change on the SCOPE perceived opportunities and satisfaction with opportunities scales (effect sizes of $d=0.25 \& 0.36$ respectively) and a change with a moderate effect size $(\mathrm{d}=0.66)$ on WEMWBS. Therefore, hypothesis 1 (b) was partially upheld.

\section{Table 3 about here}

Repeated measures multivariate analysis of covariance (MANCOVA) was used to control for the potential confounding effect of demographic characteristics (age, gender and ethnicity) and participants use of psychiatric medication (as it was associated with CPI fidelity group). There were significant CPI group by time effects found for the RG-UK $\left(\mathrm{F}(1,98)=4.81, \mathrm{p}=.03\right.$, partial $\left.\eta^{2}=.05\right)$ and the SCOPE perceived social inclusion measure $\left(\mathrm{F}(1,93)=7.06, \mathrm{p}=.01\right.$, partial $\left.\eta^{2}=.07\right)$ with moderate effect sizes (table 3$)$. There were no other significant interaction effects in these two repeated measures MANCOVAs. There were no significant CPI group by time effects found for the other SCOPE measures or WEMWBS (table 3). Figure 2 shows the adjusted effect of CPI fidelity on the outcome measures and illustrates that hypothesis $1(\mathrm{c})$ was upheld for the primary outcome and partially for the secondary outcomes.

\section{Figure 2 about here}

\section{Hypothesis 2}

The overall mean cost of services people used in the high fidelity CPI group reduced from $£ 2,775$ at pre-test to $£ 1,807$ at post-test. Mean costs in the low/moderate fidelity CPI 
group were higher, but similarly reduced over time from $£ 8,203$ at pre-test to $£ 4,092$ at posttest. The difference at post-test was statistically significant $(£ 1,331(95 \% \mathrm{CI}=£ 69$ to $£ 2593))$ which upholds hypothesis 2 .

\section{Hypothesis 3}

The quality-adjusted life years (QALYs) of people experiencing high fidelity CPI increased from .68 at pre-test to .73 at post-test and were higher than those experiencing low/moderate fidelity CPI, which similarly increased (from .51 to .61). However, the difference in change in QALY between the groups was not statistically significant (.02 $(95 \% \mathrm{CI}=-.03$ to .06$))$. Hypothesis 3 was not upheld.

\section{Discussion and Applications to Social Work}

This is the first intervention study to evaluate the effect of health and social care practice on access to social capital for people with mental health problems or a learning disability. It found that high fidelity CPI was associated with higher access to social capital over time. As the RG-UK measures the resourcefulness of networks rather than the quantity of social connections (though these are correlated (van der Gaag \& Snijders, 2005)), this finding does not confirm that the CPI helps people to enlarge their social networks. Instead, it found that the CPI was associated with participants' enhanced ability to obtain resources from their networks, which does not preclude an enlarging effect. Identifying local community resources supports the linking of individuals to a broader array of activities and services which has been suggested as a critical component to both peer-led group interventions (Gammonley \& Luken, 2001) and individually-delivered case management (Barbato et al., 2007; Rivera, Sullivan, \& Valenti, 2007). There was no difference between participants with a mental health problem and those with a learning disability, suggesting that 
both social care groups have the ability and opportunity to enhance their access to social capital, which helps people to get on and get ahead with their lives (Lin, 2001).

The other main finding was an increase in perceived social inclusion in those experiencing high fidelity CPI. This was not accompanied by other changes on the SCOPE measures of perceived opportunities and satisfaction with opportunities. High fidelity CPI requires practitioners to engage with the community of the service user to enhance their participation with it and our findings suggest that participants subjectively felt more included as a result, although there was no change in the perceived opportunities available to them. A review of 36 mental health studies found that social inclusion, a widely used term within political and policy discourses, is not a simplistic concept (Wright \& Stickley, 2013). To minimize further stigmatization of people with mental health problems by labelling them 'excluded', findings suggest clinicians should focus their efforts on promoting individuals' rights, supporting them into meaningful employment and working in ways that reduce resource inequalities. Further research is required to explore the efficacy of complex social interventions such as the CPI in enhancing individuals' social inclusion.

The finding that mental well-being improved for the whole group might be attributed to the efficacy of the participating agencies as a whole. It is possible that the CPI is primarily associated with improvements in the social domain of an individual's life. However, it was anticipated that improved social connectedness and inclusion would have a positive impact on mental well-being, but this may take longer than the nine-month study period to become evident. This is consistent with findings from a community-based rehabilitation program in Italy which found that most change in social functioning, perceived inclusion and mental wellbeing occurred within first six months followed by a plateau in next six months and then a smaller improvement in final six months (Barbato et al., 2007). Future evaluations of the 
CPI would benefit from 12-18 month follow-up to test the changes to mental wellbeing over time.

Third sector agencies achieved higher fidelity to the CPI than the National Health Service or local authority sites. Of the 30 people in the high-fidelity group, 28 of them were recruited from the third sector agencies. This suggests that the CPI is easier to implement in these agencies and more readily fits with their existing practice. This is not unexpected as third sector agencies played an important role in the development of the CPI model (Webber et al., 2015) and the National Health Service teams are dominated by a medical model which does not appear readily adaptable to complex social interventions, in spite of policy guidance aimed at orienting services towards recovery (Department of Health, 2012). Similarly, the lower service costs of the high-fidelity group could be attributed to participants largely receiving services in the third sector rather than the National Health Service or local authority. Additionally, the excess use of psychiatric medication in the low/moderate fidelity group is possibly an indication of higher levels of need in this group. The different composition of the high and low/moderate fidelity groups is a limitation of this study and needs to be resolved in future experimental studies.

This study has some important limitations which need to be considered when interpreting its findings. The CPI was piloted in a heterogenous sample to test whether it works in groups of people with different social care needs. However, our sample of adults with a learning disability was below our minimum threshold of 30 . We cannot rule out the possibility of type 1 errors in comparisons between social care groups and adequately powered further research is required within each group to obtain a more reliable estimate of the effectiveness of the CPI. Additionally, while the predominantly white British sample broadly reflected the population in England as a whole, it is not possible to generalise this study's findings to all ethnic groups. Further research is required in black and ethnic minority 
populations to explore the cultural sensitivity of the CPI. It also needs to be considered that the CPI may require adaptation to different social, cultural and mental health service contexts before generalizing the findings beyond the United Kingdom.

The absence of random allocation or a control group left us with within-group comparisons according to CPI fidelity to evaluate its likely effectiveness. As this has composition effects (an excess of participants from the third sector in the high-fidelity group), our findings need to be treated with some caution.

We did not use diagnostic criteria or a rigorous screening process in the recruitment of participants to this pilot study, which was largely conducted by practitioners. Eligibility criteria of agencies participating in the study varied, so the sample was heterogeneous. While this permitted a naturalistic evaluation of the CPI, it limits our ability to generalise our findings to any particular diagnostic group.

A follow-up period from pretest to posttest of twelve months was originally planned, but this had to be shortened to nine months due to delays in participant recruitment. A longer follow-up period is required in future experimental evaluations of the CPI as social connections can take a long time to develop and become resourceful for an individual.

The CPI model articulates processes which are evident in good social work practice (Webber et al., 2016). Practitioners who were trained in the CPI were from diverse professional groups, although the majority were social workers or social care workers. These practitioners reported that the CPI model largely mapped onto their existing practice, though mental health social workers in the National Health Service sites expressed concern that they were unable to implement the model fully because their roles did not permit it. Crisis work and statutory responsibilities as Approved Mental Health Professionals largely meant that these social workers were unable to spend the required time developing contacts within individuals' communities to enhance their social connections. Although building community 
connections is defined as a key role of mental health social workers (Allen, 2014), it is apparent that their current responsibilities make this a difficult role to perform. The findings of this study suggest that if social work practice can become more oriented towards service users' communities it can improve their social outcomes. However, further experimental evaluation of the CPI is required to confirm this, particularly in statutory agencies such as the National Health Service in England. 


\section{References}

Allen, E. S., \& Baucom, D. H. (2004). Adult Attachment and Patterns of Extradyadic Involvement. Family Process, 43(4), 467-488 doi:10.1111/j.1545-5300.2004.00035.x.

Allen, R. (2014). The Role of the Social Worker in Adult Mental Health Services. London: The College of Social Work.

Almedom, A. M., \& Glandon, D. (2007). Social capital and mental health: an updated interdisciplinary review of primary evidence. In I. Kawachi, S. V. Subramanian \& D. Kim (Eds.), Social capital and health (pp. 191-214). New York: Springer-Verlag.

Anderson, K., Laxhman, N., \& Priebe, S. (2015). Can mental health interventions change social networks? A systematic review. BMC Psychiatry, 15(1), 297 doi:10.1186/s12888-015-0684-6.

Attree, P., French, B., Milton, B., Povall, S., Whitehead, M., \& Popay, J. (2011). The experience of community engagement for individuals: a rapid review of evidence. Health \& Social Care in the Community, 19(3), 250-260 doi:10.1111/j.13652524.2010.00976.x.

Barbato, A., Agnetti, G., D'Avanzo, B., Frova, M., Guerrini, A., \& Tettamanti, M. (2007). Outcome of community-based rehabilitation program for people with mental illness who are considered difficult to treat. J Rehabil Res Dev, 44(6), 775-783 doi:10.1682/JRRD.2007.02.0041.

Bartholomew, K., \& Horowitz, L. M. (1991). Attachment styles among young adults: A test of a four-category model. Journal of Personality and Social Psychology, 61(2), 226244 doi:dx.doi.org/10.1037/0022-3514.61.2.226 
Bates, P., \& Davis, F. A. (2004). Social capital, social inclusion and services for people with learning disabilities. Disability and Society, 19(3), 195-207 doi:doi.org/10.1080/0968759042000204202.

Beecham, J. K., \& Knapp, M. R. J. (2001). Costing psychiatric interventions. In G. Thornicroft, C. Brewin \& J. K. Wing (Eds.), Measuring mental health needs (2nd ed.). London: Gaskell.

Bigby, C., \& Wiesel, I. (2011). Encounter as a dimension of social inclusion for people with intellectual disability: Beyond and between community presence and participation. Journal of Intellectual \& Developmental Disability, 36(4), 259-263 doi:10.3109/13668250.2011.619166

Boardman, J. (2011). Social exclusion and mental health - How people with mental health problems are disadvantaged: An overview. Mental Health and Social Inclusion, 15(3), 112-121 doi:10.1108/20428301111165690.

Carter, R., Satcher, D., \& Coelho, T. (2013). Addressing Stigma Through Social Inclusion. American Journal of Public Health, 103(5), 773-773 doi:10.2105/AJPH.2012.301167.

Ciechanowski, P., Walker, E., Katon, W., \& Russo, J. (2002). Attachment Theory: A Model for Health Care Utilization and Somatization. Psychosomatic Medicine, 64(4), 660667 doi:10.1097/01.PSY.0000021948.90613.76.

Collom, E. (2008). Engagement of the elderly in time banking: The potential for social capital generation in an aging society. Journal of Aging and Social Policy, 20(4), 414436 doi:10.1080/08959420802186282.

Coombs, T., Nicholas, A., \& Pirkis, J. (2013). A review of social inclusion measures. The Australian and New Zealand journal of psychiatry, 47(10), 906-919 doi:10.1177/0004867413491161. 
Curtis , L., \& Burns, A. (2015). Unit Costs of Health and Social Care. Canterbury: PSSRU, University of Kent.

Department of Health. (2012). No Health Without Mental Health: Mental Health Strategy Implementation Framework Guidance. London: Department of Health.

Department of Health. (2013). No Health Without Mental Health. Mental Health Dashboard. London: Department of Health.

Department of Health. (2016). Social Work for Better Mental Health. A Strategic Statement. London: Department of Health.

Dieperink, M., Leskela, J., Thuras, P., \& Engdahl, B. (2001). Attachment Style Classification and Posttraumatic Stress Disorder in Former Prisoners of War. American Journal of Orthopsychiatry, 71(3), 374-378 doi:10.1037/0002-9432.71.3.374.

Drake, K. E., Bull, R., \& Boon, J. C. W. (2008). Interrogative suggestibility, self-esteem, and the influence of negative life-events. Legal and Criminological Psychology, 13(2), 299-307 doi:10.1348/135532507X209981.

Dutt, K., \& Webber, M. (2010). Access to Social Capital and Social Support Among South East Asian Women With Severe Mental Health Problems: a Cross-Sectional Survey. International Journal of Social Psychiatry, 56(6), 593-605 doi:10.1177/0020764009106415.

Evans-Lacko, S., Henderson, C., \& Thornicroft, G. (2013). Public knowledge, attitudes and behaviour regarding people with mental illness in England 2009-2012. The British Journal of Psychiatry, 202(s55), s51-s57 doi:10.1192/bjp.bp.112.112979.

Fiorillo, A., Luciano, M., Del Vecchio, V., Sampogna, G., Obradors-Tarrago, C., Maj, M., \& Consortium, R. (2013). Priorities for mental health research in Europe: A survey among national stakeholders' associations within the ROAMER project. World Psychiatry, 12(2), 165-170 doi:10.1002/wps.20052. 
Flap, H. (1999). Creation and returns of social capital. A new research program. La Revue Tocqueville, $X X(1), 5-26$

Gammonley, D., \& Luken, K. (2001). Peer education and advocacy through recreation and leadership. Psychiatric Rehabilitation Journal, 25(2), 170-178 doi:10.1037/h0095028.

Gayer-Anderson, C., \& Morgan, C. (2013). Social networks, support and early psychosis: a systematic review. Epidemiology and Psychiatric Sciences, 22(2), 131-146 doi:10.1017/s2045796012000406.

Henderson, R. C., Corker, E., Hamilton, S., Williams, P., Pinfold, V., Rose, D., . . . Thornicroft, G. (2014). Viewpoint survey of mental health service users' experiences of discrimination in England 2008-2012. Social Psychiatry \& Psychiatric Epidemiology. doi:10.1007/s00127-014-0875-3.

Hobfoll, S. E. (1998). Stress, Culture and Community: The Psychology and Philosphy of Stress. New York: Plenum Press.

Holt-Lunstad, J., Smith, T. B., Baker, M., Harris, T., \& Stephenson, D. (2015). Loneliness and Social Isolation as Risk Factors for Mortality. Perspectives on Psychological Science, 10(2), 227-237 doi:10.1177/1745691614568352.

Howarth, S., Morris, D., Newlin, M., \& Webber, M. (2016). Health and social care interventions which promote social participation for adults with learning disabilities: a review. British Journal of Learning Disabilities, 44(1), 3-15 doi:10.1111/bld.12100.

Huxley, P., Evans, S., Madge, S., Webber, M., Burchardt, T., McDaid, D., \& Knapp, M. (2012). Development of a social inclusion index to capture subjective and objective life domains (Phase II): psychometric development study, NIHR Health Technology Assessment Programme. Health Technology Assessment, 16 (1) doi:10.3310/hta16010. 
Iwasaki, Y., Coyle, C., \& Shank, J. (2010). Leisure as a context for active living, recovery, health and life quality for persons with mental illness in a global context. Health Promotion International, 25, 483-494 doi:10.1093/heapro/daq037.

Jenson, J. M. (2014). Science, Social Work, and Intervention Research: The Case of Critical Time Intervention. Research on Social Work Practice, 24(5), 564-570 doi:10.1177/1049731513517144.

Kawachi, I., Subramanian, S. V., \& Kim, D. (Eds.). (2007). Social capital and health. New York: Springer-Verlag.

Kobayashi, T., Kawachi, I., Iwase, T., Suzuki, E., \& Takao, S. (2013). Individual-level social capital and self-rated health in Japan: an application of the Resource Generator. Social Science and Medicine, 85, 32-37 doi:10.1016/j.socscimed.2013.02.027.

Lancaster, G. A., Dodd, S., \& Williamson, P. R. (2004). Design and analysis of pilot studies: recommendations for good practice. Journal of Evaluation in Clinical Practice, 10(2), 307-312 doi:10.1111/j.2002.384.

Leu, J. X., Yen, I. H., Gansk, S. A., Walton, E., Adler, N. E., \& Takeuchi, D. T. (2008). The association between subjective social status and mental health among Asian immigrants: Investigating the influence of age at immigration. Social Science \& Medicine, 66(5), 1152-1164 doi:10.1016/j.socscimed.2007.11.028.

Lin, N. (2001). Social Capital. A Theory of Social Structure and Action. Cambridge: Cambridge University Press.

Lin, N., \& Dumin, M. (1986). Access to occupations through social ties. Social Networks, 8, 365-385 doi:10.1016/0378-8733(86)90003-1.

Lin, N., \& Erickson, B. (Eds.). (2008). Social capital. An international research program. Oxford: Oxford University Press. 
Lloyd, C., King, R., \& McCarthy, M. (2007). The association between leisure motivation and recovery: a pilot study. Australian Journal of Occupational Therapy, 54, 33-41 doi:10.1111/j.1440-1630.2006.00648.x.

Maheswaran, H., Weich, S., Powell, J., \& Stewart-Brown, S. (2012). Evaluating the responsiveness of the Warwick Edinburgh Mental Well-Being Scale (WEMWBS): Group and individual level analysis. Health and Quality of Life Outcomes, 10(1), 156 doi:10.1186/1477-7525-10-156.

McCallister, L., \& Fischer, C. (1978). A procedure for surveying personal networks. Sociological Methods and Research, 7, 131-148 doi:10.1177/004912417800700202.

McConkey, R., \& Collins, S. (2010). The role of support staff in promoting the social inclusion of persons with an intellectual disability. Journal of Intellectual Disability Research, 54(8), 691-700 doi:10.1111/j.1365-2788.2010.01295.x.

McPherson, K., Kerr, S., McGee, E., Morgan, A., Cheater, F., McLean, J., \& Egan, J. (2014). The association between social capital and mental health and behavioural problems in children and adolescents: an integrative systematic review. BMC Psychology, 2(1), 7 doi:10.1186/2050-7283-2-7.

Medical Research Council. (2008). Developing and Evaluating Complex Interventions: New Guidance. London: Medical Research Council.

Murray, J., Easter, A., \& Bellringer, S. (2007). Evaluation of Capital Volunteering. 3rd interim report:outcomes and experiences at six months. London: Health Service \& Population Research Department, Institute of Psychiatry, King's College London.

Newlin, M., Morris, D., Howarth, S., \& Webber, M. (2015). Social participation interventions for adults with mental health problems: A review and narrative synthesis. Social Work Research, 39(3), 167-180 doi:10.1093/swr/svv015. 
Norbeck, J. S. (1984). Modification of recent life event questionnaires for use with female respondents. Research in Nursing and Health, 7, 61-71 doi:10.1002/nur.4770070110.

Norbeck, J. S., \& Anderson, N. J. (1989). Psychosocial Predictors of Pregnancy Outcomes in Low-Income Black, Hispanic, and White Women. Nursing Research, 38(4), 204-209 doi:10.1097/00006199-198907000-00004.

Putnam, R. (1993). Making Democracy Work: Civic Traditions in Modern Italy. Princeton, NJ: Princeton University Press.

Rivera, J. J., Sullivan, A. M., \& Valenti, S. S. (2007). Adding Consumer-Providers to Intensive Case Management: Does It Improve Outcome? Psychiatric Services, 58(6), 802-809 doi:10.1176/ps.2007.58.6.802.

Sayce, L. (2000). From Psychiatric Patient to Citizen. Overcoming Discrimination and Social Exclusion. London: Macmillan.

Schomerus, G., Schwahn, C., Holzinger, A., Corrigan, P. W., Grabe, H. J., Carta, M. G., \& Angermeyer, M. C. (2012). Evolution of public attitudes about mental illness: a systematic review and meta-analysis. Acta Psychiatrica Scandinavica, 125(6), 440452 doi:10.1111/j.1600-0447.2012.01826.x.

Snethen, G., McCormick, B. P., \& Van Puymbroeck, M. (2012). Community involvement, planning and coping skills: pilot outcomes of a recreational-therapy intervention for adults with schizophrenia. Disability and Rehabilitation, 34(18), 1575-1584 doi:10.3109/09638288.2011.650315.

Song, L. (2011). Social capital and psychological distress. Journal of Health and Social Behavior, 52(4), 478-492 doi:10.1177/0022146511411921.

Song, L. (2015). Does who you know in the positional hierarchy protect or hurt? Social capital, comparative reference group, and depression in two societies. Social Science and Medicine, 136-137, 117-127 doi:10.1016/j.socscimed.2015.05.012. 
Song, L., \& Chang, T.-Y. (2012). Do resources of network members help in help seeking? Social capital and health information search. Social Networks, 34(4), 658-669 doi:10.1016/j.socnet.2012.08.002.

Stain, H. J., Galletly, C. A., Clark, S., Wilson, J., Killen, E. A., Anthes, L., . . Harvey, C. (2012). Understanding the social costs of psychosis: The experience of adults affected by psychosis identified within the second Australian national survey of psychosis. Australian and New Zealand Journal of Psychiatry, 46(9), 879-889 doi:10.1177/0004867412449060.

Stewart-Brown, S., Platt, S., Tennant, A., Maheswaran, H., Parkinson, J., Weich, S., . . Clarke, A. (2011). The Warwick-Edinburgh Mental Well-being Scale (WEMWBS): a valid and reliable tool for measuring mental well-being in diverse populations and projects. Journal of Epidemiology and Community Health, 65(Suppl 2), A38-A39 doi:10.1136/jech.2011.143586.86.

Sun, X., Liu, K. U. N., Webber, M., \& Shi, L. (2017). Individual social capital and healthrelated quality of life among older rural Chinese. Ageing and Society, 37(2), 221-242 doi:10.1017/S0144686X15001099.

Tennant, R., Hiller, L., Fishwick, R., Platt, S., Joseph, S., Weich, S., . . Stewart-Brown, S. (2007). The Warwick-Edinburgh Mental Well-being Scale (WEMWBS): development and UK validation. Health and Quality of Life Outcomes, 5(1), 63 doi:10.1186/1477-7525-5-63.

The EuroQol Group. (1990). EuroQol - a new facility for the measurement of health related quality of life. Health Policy, 16, 199-208 doi:10.1016/0168-8510(90)90421-9.

Thornicroft, G. (2006). Shunned: Discrimination Against People with Mental Illness. Oxford: Oxford University Press. 
van der Gaag, M., \& Snijders, T. A. B. (2005). The Resource Generator: social capital quantification with concrete items. Social Networks, 27(1), 1-29 doi:10.1016/j.socnet.2004.10.001.

Webber, M. (2014). From ethnography to randomised controlled trial: An innovative approach to developing complex social interventions. Journal of Evidence-Based Social Work, 11, 173-182 doi:10.1080/15433714.2013.847265.

Webber, M., Corker, E., Hamilton, S., Weeks, C., Pinfold, V., Rose, D., . . Henderson, C. (2014). Discrimination against people with severe mental illness and their access to social capital: findings from the Viewpoint survey. Epidemiology and Psychiatric Sciences, 23(2), 155-165 doi:10.1017/S2045796013000243.

Webber, M., \& Fendt-Newlin, M. (2017). A review of social participation interventions for people with mental health problems. Social Psychiatry and Psychiatric Epidemiology, 52(4), 369-380 doi:10.1007/s00127-017-1372-2.

Webber, M., \& Huxley, P. (2007). Measuring access to social capital: The validity and reliability of the Resource Generator-UK and its association with common mental disorder. Social Science and Medicine, 65 (3), 481-492 doi:10.1016/j.socscimed.2007.03.030.

Webber, M., Huxley, P., \& Harris, T. (2011). Social capital and the course of depression: sixmonth prospective cohort study. Journal of Affective Disorders, 129 (1-2), 149-157 doi:10.1016/j.jad.2010.08.005.

Webber, M., Reidy, H., Ansari, D., Stevens, M., \& Morris, D. (2015). Enhancing social networks: a qualitative study of health and social care practice in UK mental health services. Health and Social Care in the Community, 23(2), 180-189 doi:10.1111/hsc.12135. 
Webber, M., Reidy, H., Ansari, D., Stevens, M., \& Morris, D. (2016). Developing and modelling complex social interventions: introducing the Connecting People Intervention. Research on Social Work Practice, 26(1), 14-19 doi:10.1177/1049731515578687.

Wright, N., \& Stickley, T. (2013). Concepts of social inclusion, exclusion and mental health: a review of the international literature. Journal of Psychiatric and Mental Health Nursing, 20, 71-81 doi:10.1111/j.1365-2850.2012.01889.x.

Zambon, A., Morgan, A., Vereecken, C., Colombini, S., Boyce, W., Mazur, J., . . Cavallo, F. (2010). The contribution of club participation to adolescent health: Evidence from six countries. Journal of Epidemiology and Community Health, 64(1), 89-95 doi:10.1136/jech.2009.088443.

Zoppei, S., Lasalvia, A., Bonetto, C., Bortel, T., Nyqvist, F., Webber, M., . . Thornicroft, G. (2014). Social capital and reported discrimination among people with depression in 15 European countries. Social Psychiatry and Psychiatric Epidemiology, 10.1007/s00127-00014-00856-00126 doi:10.1007/s00127-014-0856-6. 
Tables and figures

Table 1. Characteristics of the sample at post-test by CPI fidelity group

\begin{tabular}{|c|c|c|c|c|c|c|c|}
\hline & \multicolumn{2}{|c|}{$\begin{array}{l}\text { High fidelity CPI } \\
\qquad(\mathrm{n}=30)\end{array}$} & \multicolumn{2}{|c|}{$\begin{array}{c}\text { Low/moderate } \\
\text { fidelity CPI }(n=87)\end{array}$} & \multicolumn{2}{|c|}{ Total $(n=117)$} & \\
\hline & $\%$ & (n) & $\%$ & (n) & $\%$ & (n) & \\
\hline \multicolumn{8}{|l|}{ Service user group } \\
\hline Mental health & 83.3 & 25 & 82.8 & 72 & 82.9 & 97 & $\chi^{2}=.01, \mathrm{df}=1, \mathrm{p}=.94$ \\
\hline Learning disability & 16.7 & 5 & 17.2 & 15 & 17.1 & 20 & \\
\hline Sex (\% female) & 63.3 & 19 & 46.0 & 40 & 50.4 & 59 & $\chi^{2}=2.69, \mathrm{df}=1, \mathrm{p}=.10$ \\
\hline Ethnic group (\% not white British) & 23.3 & 7 & 14.9 & 13 & 17.1 & 20 & $\chi^{2}=1.11, \mathrm{df}=1, \mathrm{p}=.29$ \\
\hline Age & \multicolumn{2}{|c|}{$\mathrm{M}=43.1, \mathrm{SD}=14.8$} & \multicolumn{2}{|c|}{$\mathrm{M}=43.8, \mathrm{SD}=19.2$} & \multicolumn{2}{|c|}{$\mathrm{M}=43.6, \mathrm{SD}=18.1$} & $\mathrm{t}=.17, \mathrm{df}=115, \mathrm{p}=.87$ \\
\hline Taking psychiatric medication & 63.3 & 19 & 86.0 & 74 & 80.2 & 93 & $\chi^{2}=7.22, \mathrm{df}=1, \mathrm{p}=.01$ \\
\hline Employed & 0 & 0 & 12.6 & 11 & 9.4 & 11 & Fisher's Exact $p=.06$ \\
\hline Multiple deprivation score ${ }^{1}$ & \multicolumn{2}{|c|}{ Median=8,020 } & \multicolumn{2}{|c|}{ Median=11,073 } & \multicolumn{2}{|c|}{ Median=10,303 } & Mann Whitney $U=967, p=.12$ \\
\hline Vehicle in household & 37.9 & 11 & 51.7 & 45 & 48.3 & 56 & $\chi^{2}=1.66, \mathrm{df}=1, \mathrm{p}=.20$ \\
\hline Income above $£ 13,500$ pa & 3.7 & 1 & 13.0 & 10 & 10.6 & 11 & $\chi^{2}=1.82, \mathrm{df}=1, \mathrm{p}=.18$ \\
\hline Secure attachment style & 23.3 & 7 & 35.3 & 30 & 32.2 & 37 & $\chi^{2}=1.45, \mathrm{df}=1, \mathrm{p}=.23$ \\
\hline Life events $^{2}$ & \multicolumn{2}{|c|}{$\mathrm{M}=6.60, \mathrm{SD}=8.9$} & \multicolumn{2}{|c|}{$\mathrm{M}=1.9, \mathrm{SD}=10.6$} & \multicolumn{2}{|c|}{$\mathrm{M}=3.1, \mathrm{SD}=10.3$} & $\mathrm{t}=2.19, \mathrm{df}=114, \mathrm{p}=.03$ \\
\hline
\end{tabular}

${ }^{1}$ Postcode rank on Index of Social Deprivation (lower rank=higher deprivation)

${ }^{2}$ Balance of positive and negative life events (higher score=more positive life events) 
Table 2. Pretest-posttest changes on outcome measures for participants by CPI fidelity

\begin{tabular}{|c|c|c|c|c|c|c|c|}
\hline & \multicolumn{3}{|c|}{ Pretest } & \multicolumn{3}{|c|}{ Posttest } & \multirow[b]{2}{*}{$\begin{array}{l}\text { Effect size } \\
\text { (Cohen's d) }\end{array}$} \\
\hline & $\mathrm{M}$ & SD & $\begin{array}{c}\text { 95\% Confidence } \\
\text { Interval }\end{array}$ & M & $\mathrm{SD}$ & $\begin{array}{l}\text { 95\% Confidence } \\
\text { Interval }\end{array}$ & \\
\hline \multicolumn{8}{|l|}{ High fidelity $(\mathrm{n}=30)$} \\
\hline \multicolumn{8}{|l|}{ Access to social capital (RG-UK) } \\
\hline Total scale & 10.13 & 5.41 & {$[8.11,12.15]$} & 13.20 & 5.46 & {$[11.16,15.24]$} & $0.51 * *$ \\
\hline Domestic resources & 3.10 & 1.83 & {$[2.42,3.78]$} & 3.67 & 1.83 & {$[2.96,4.37]$} & 0.34 \\
\hline Expert advice & 2.90 & 1.97 & {$[2.16,3.64]$} & 3.77 & 2.37 & {$[2.88,4.65]$} & 0.33 \\
\hline Personal skills & 1.83 & 1.66 & {$[1.21,2.45]$} & 2.60 & 1.57 & {$[2.01,3.19]$} & $0.39 *$ \\
\hline Problem solving skills & 2.30 & 1.26 & {$[1.83,2.77]$} & 3.17 & 1.15 & {$[2.74,3.60]$} & $0.69 * * *$ \\
\hline \multicolumn{8}{|l|}{ Social inclusion (SCOPE) } \\
\hline Perceived opportunities & 2.92 & 0.84 & {$[2.56,3.27]$} & 2.95 & 0.60 & {$[2.59,3.31]$} & 0.06 \\
\hline Satisfaction with opportunities & 4.48 & 0.84 & {$[4.11,4.85]$} & 5.09 & 0.82 & {$[4.57,5.61]$} & 0.55 \\
\hline Perceived social inclusion & 4.13 & 1.63 & {$[3.52,4.74]$} & 5.00 & 1.73 & {$[4.34,5.66]$} & $0.52 * *$ \\
\hline Mental well-being (WEMWBS) & 37.43 & 9.29 & {$[33.97,40.89]$} & 44.33 & 15.07 & {$[38.71,49.96]$} & $0.53 * *$ \\
\hline \multicolumn{8}{|l|}{ Low/moderate fidelity $(n=86)$} \\
\hline \multicolumn{8}{|l|}{ Access to social capital (RG-UK) } \\
\hline Total scale & 12.27 & 6.45 & {$[10.89,13.65]$} & 12.13 & 6.54 & {$[10.73,13.53]$} & 0.01 \\
\hline Domestic resources & 3.70 & 2.17 & {$[3.23,4.16]$} & 3.59 & 2.10 & {$[3.14,4.04]$} & 0.02 \\
\hline Expert advice & 3.40 & 2.59 & {$[2.84,3.95]$} & 3.29 & 2.65 & {$[2.72,3.86]$} & 0.03 \\
\hline Personal skills & 2.53 & 1.64 & {$[2.18,2.89]$} & 2.55 & 1.73 & {$[2.18,2.92]$} & 0.03 \\
\hline Problem solving skills & 2.64 & 1.26 & {$[2.37,2.91]$} & 2.70 & 1.23 & {$[2.43,2.96]$} & 0.08 \\
\hline \multicolumn{8}{|l|}{ Social inclusion (SCOPE) } \\
\hline Perceived opportunities & 2.50 & 0.87 & {$[2.30,2.71]$} & 2.70 & 0.81 & {$[2.50,2.89]$} & $0.25 *$ \\
\hline Satisfaction with opportunities & 4.29 & 1.03 & {$[4.05,4.54]$} & 4.48 & 0.86 & {$[4.26,4.71]$} & $0.36^{*}$ \\
\hline Perceived social inclusion & 3.87 & 1.85 & {$[3.48,4.27]$} & 4.06 & 1.80 & {$[3.67,4.46]$} & 0.11 \\
\hline Mental well-being (WEMWBS) & 34.94 & 12.06 & {$[32.37,37.51]$} & 40.73 & 12.33 & {$[38.07,43.39]$} & $0.66^{* * *}$ \\
\hline
\end{tabular}

$* \mathrm{p}<0.05, * * \mathrm{p}<0.01, * * * \mathrm{p}<0.001$ 
Table 3. Interaction effects for CPI fidelity groups as identified by repeated measures MANCOVAs ${ }^{1}$

\begin{tabular}{llccccc}
\hline Measure & \multicolumn{1}{c}{ Variables $^{2}$} & df & Mean Square & F & $p$ & ${\text { Partial } \eta^{2}}^{2}$ \\
\hline RG-UK total scale & Time & 1 & 77.65 & 6.21 & 0.01 & 0.06 \\
SCOPE perceived opportunities & Time x CPI group & 1 & 60.16 & 4.81 & 0.03 & 0.05 \\
\multirow{2}{*}{ SCOPE satisfaction with opportunities } & Time & 1 & 0.26 & 1.00 & 0.32 & 0.02 \\
SCOPE perceived social inclusion & Time x CPI group & 1 & 0.15 & 0.57 & 0.46 & 0.01 \\
& Time & 1 & 0.70 & 2.38 & 0.13 & 0.05 \\
WEMWBS & Time x CPI group & 1 & 0.40 & 1.34 & 0.25 & 0.03 \\
& Time & 1 & 0.01 & 0.01 & 0.93 & 0.00 \\
& Time x CPI group & 1 & 12.01 & 7.06 & 0.01 & 0.07 \\
\hline
\end{tabular}

${ }^{1}$ Covariates entered into the model $=$ age, gender, ethnicity, taking psychiatric medication

${ }^{2}$ Interaction effects of covariates were not statistically significant and are omitted for brevity 
Figure 1. Participant Flow Chart

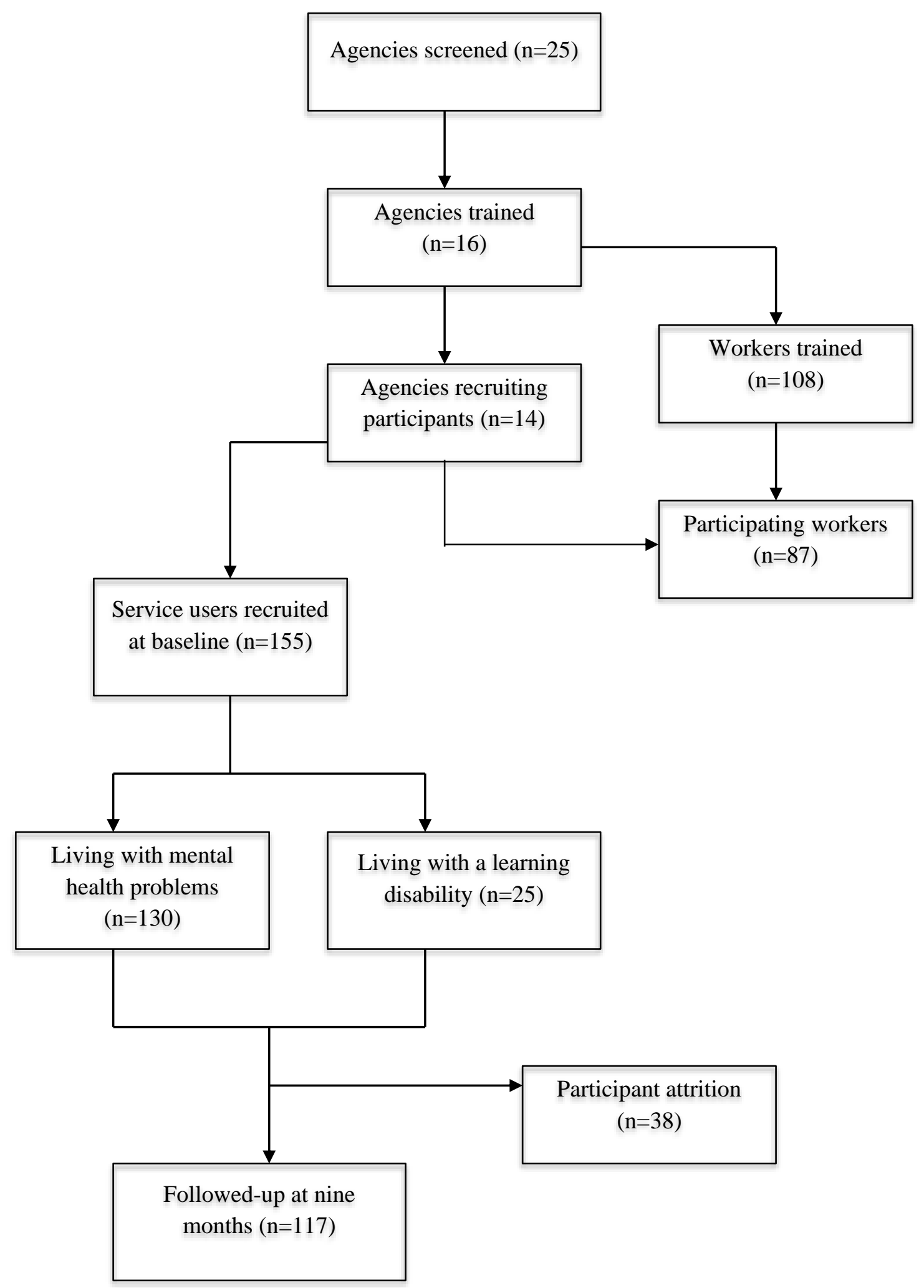


Figure 2. Estimated marginal means of outcome measures adjusted for age, gender, ethnicity and psychiatric medication use

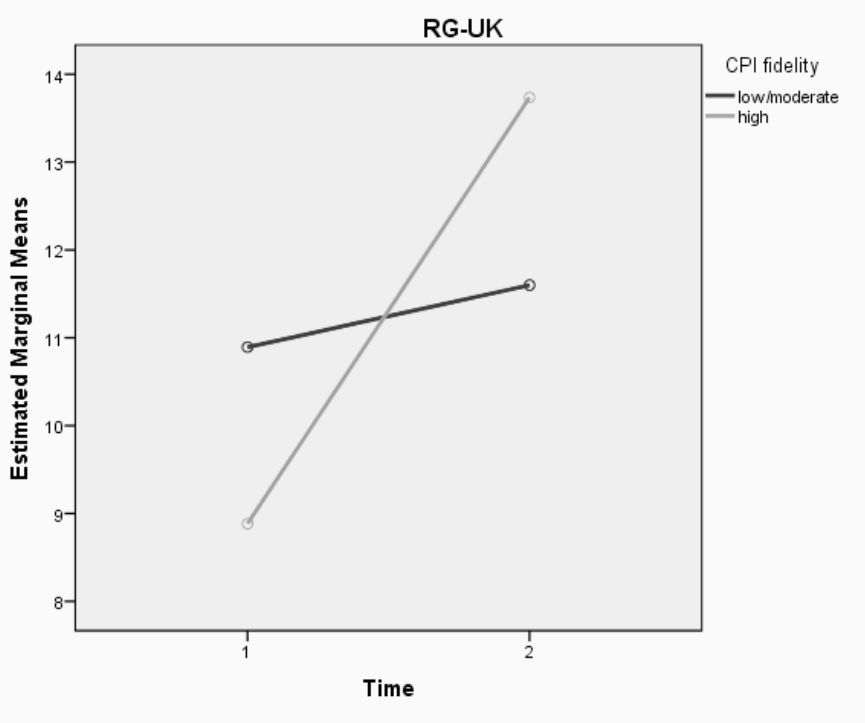

Covariates appearing in the model are evaluated at the following values: $\mathrm{Age}=43.88$

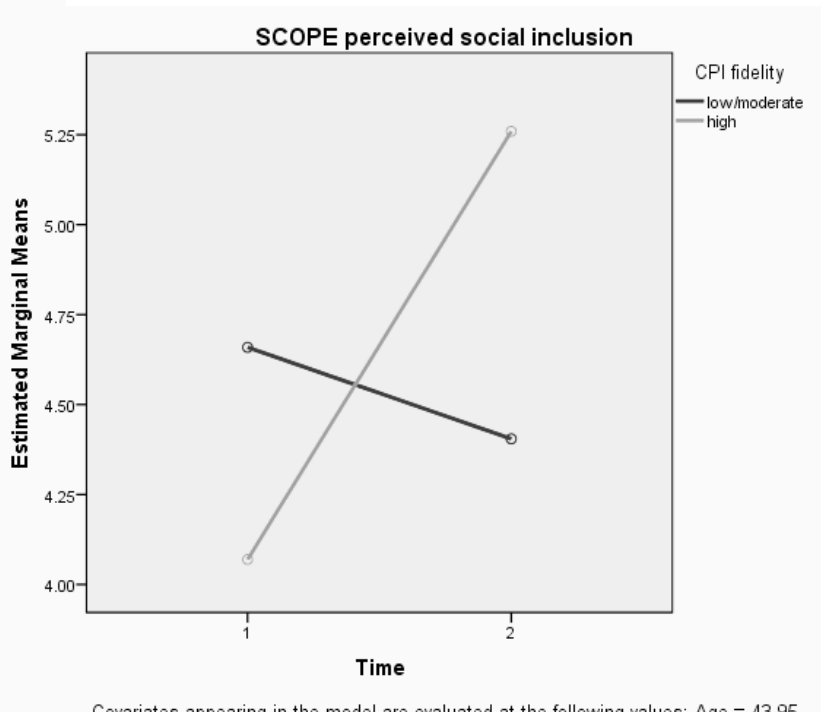

Covariates appearing in the model are evaluated at the following values: $\mathrm{Age}=43.95$

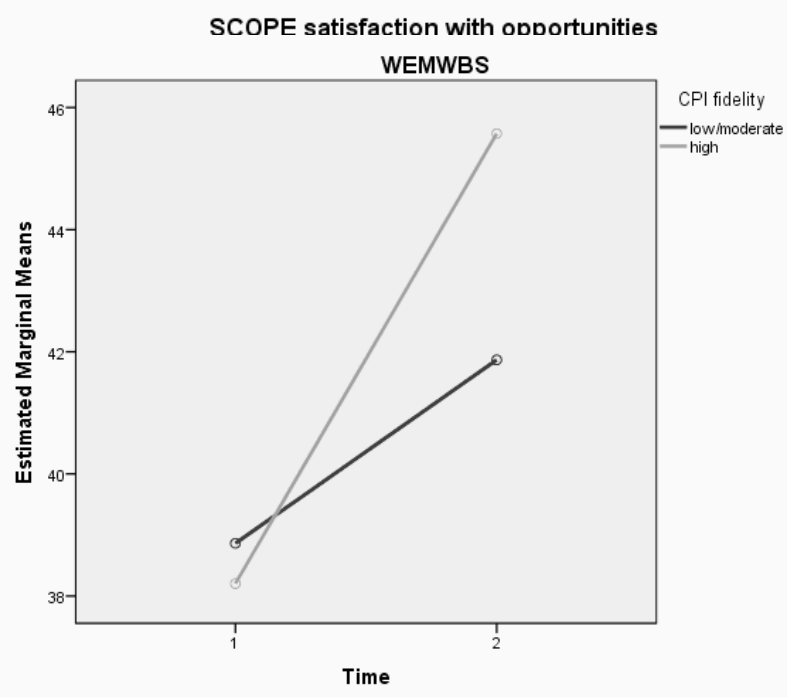

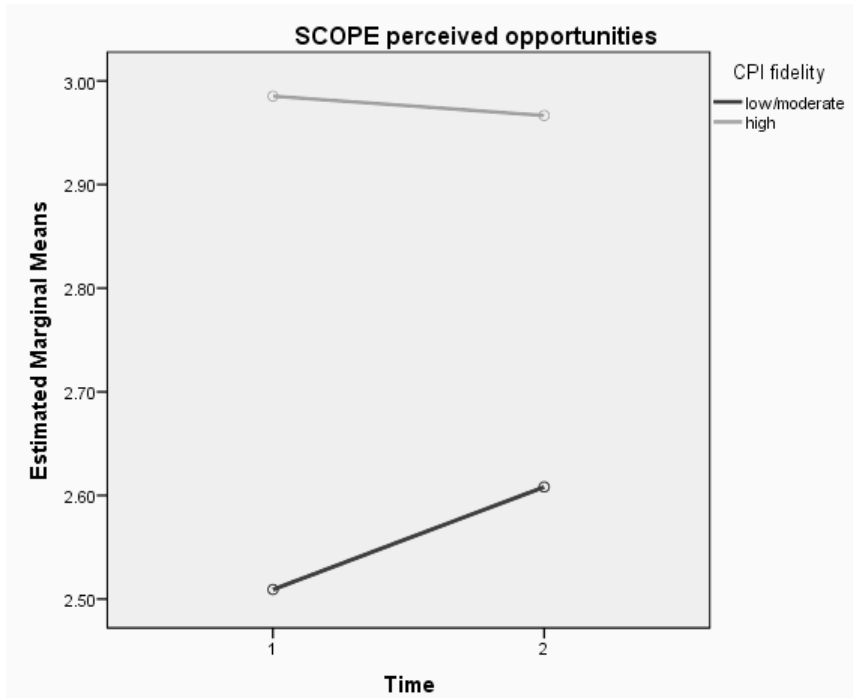

